www.jmscr.igmpublication.org

Impact Factor (SJIF): 6.379

Index Copernicus Value: 71.58

ISSN (e)-2347-176x ISSN (p) 2455-0450

crossref DOI: _https://dx.doi.org/10.18535/jmscr/v6i3.192

Journal Of Medical Science And Clinical Research

\title{
Study of coagulation profile in hepatic disorders in a Tertiary Care Centre
}

\author{
Authors \\ Takutila M Ozukum, Sandhya Gulati, Nidhi Sharma, Gaurav Kumar Gupta ${ }^{1}$ \\ Department of Pathology, Gastroenterology ${ }^{1}$, SMS Medical College and Hospital, Jaipur \\ Corresponding Author \\ Takutila M Ozukum \\ Room no. 317, SMS girls hostel, Jaipur, Rajasthan, 302004. India \\ Email: scarlett.ozukum@gmail.com, Phone no.9929350372
}

\begin{abstract}
Introduction: Liver plays the important role of synthesis of coagulation and anti coagulation proteins. Thus derangement of liver functions can lead to alteration and abnormal balance of these pathways.

Materials and Methods: The study included 170 cases of diagnosed liver diseases in the gastroenterology ward. PT, APTT and platelet count were the parameters evaluated.

Results: Out of the total 170 cases, $130(76.50 \%)$ cases had altered coagulation profile. Out of 115 cases of liver cirrhosis, PT, APTT and platelet count were altered in 71.3\%, 81.7\% and $52.2 \%$ respectively. In 24 cases of liver abscess, PT, APTT and platelet count were altered in 58.3\%, 58.3\% and $4.1 \%$ respectively. In the remaining 31 cases, PT, APTT and platelet count were altered in $40 \% .36 .7 \%$ and $12.9 \%$ respectively.

Conclusion: Coagulation profile was found to be significantly altered in patients with liver disease.

Keywords: Liver, coagulation, platelet, prothrombin.
\end{abstract}

\section{Introduction}

Liver is the largest organ in the body weighing 1$1.5 \mathrm{Kg}$ and representing $1.5-2.5 \%$ of the lean body mass ${ }^{[1]}$. Liver disease is one of the leading cause of mortality and morbidity in India. Coagulation is one of the most important and constantly measured parameter in liver diseases. Liver is involved in both the coagulation and anti coagulation pathway, and in a normal state it maintains the balance between the two pathways. The major alterations in the hemostatic pathway in most patients with liver disease includes thrombocytopenia, altered endothelial functions, reduced clotting factors, hyperfibrinolysis and dysfibrinogenemia. Deranged coagulation is one of the prognostic marker in liver disease and has been included in the Child Pugh scoring system and also the MELD (model for end stage liver disease) scoring system ${ }^{[2]}$. Primary coagulation profile - platelet count, prothrombin time (PT) and activated partial thromboplastin time (APTT) are some of the routine test requested in patients with liver disease.

\section{Materials and Methods}

Blood samples of 170 consecutive cases of clinically diagnosed liver disease received in the hematology laboratory from the gastroenterology ward were evaluated. The study included all cases of liver diseases. PT, APTT and platelet count 
were the parameters evaluated. Blood sample for PT and APTT was collected in trisodium citrate vial while EDTA vial was used for platelet count. PT and APTT were performed in STA Compact (a fully automated coagulation analyser). Platelet count was done in automated hematology analyser (Sysmex XT4000i).

\section{Results}

A total of 170 cases of liver disease were studied. The age range was $17-70$ years with a mean of $43.92 \pm 12.01$ years. Out of the total 170 cases, $130(76.50 \%)$ cases had altered coagulation profile while it was normal in $40(23.5 \%)$ cases. The proportion of altered coagulation profile was as shown in table 1 .

Sex distribution was 139 male $(81.8 \%)$ and 31 (18.2\%) females. Out of 139 male patients, 106 (76.3\%) cases had altered coagulation profile. Out of 31 female patients, $24(77.4 \%)$ cases had altered coagulation profile. On comparing the coagulation profile in male and female patients, $p$ value was found to be $0.395,0.980$ and 0.823 for PT, APTT and platelet count respectively. $\mathrm{p}$ value $<0.05$ was taken as significant, so there was no significant correlation between the alteration of coagulation profile between males and females.

The distribution of liver diseases in the present study were - cirrhosis 115 (68.2\%), liver abscess 24 (14.1\%), liver SOL 10 (5.9\%), alcoholic hepatitis 7 (4.2\%), acute viral hepatitis $8(4.7 \%)$ and fatty liver $6(2.9 \%)$. The coagulation profile in various liver diseases were as shown in table 2 , table 3 and table 4.

Out of 170 cases, 115 cases had liver cirrhosis. The various causes of cirrhosis were - alcohol (67.8\%), hepatitis B (14\%), non alcoholic steatohepatitis (3.5\%), hepatitis C (1.7\%), autoimmune $(1.7 \%)$ and unknown etiology $(11.3 \%)$. The coagulation profile in cirrhosis were as shown in table 5.

The mean PT, APTT and platelet count in alcoholic cirrhosis was $24.24 \pm 12$ seconds, $50.1 \pm$ 18.12 seconds and $114.83 \pm 83.39 \times 10^{6} / \mathrm{dl}$ respectively with alteration seen in $73.08 \%$, $82.05 \%$ and $53.8 \%$ cases respectively. The mean PT, APTT and platelet count in non alcoholic cirrhosis was $19.99 \pm 6.47$ seconds, $49.22 \pm 17$ seconds and $146.57 \pm 136.51 \times 10^{6} / \mathrm{dl}$ respectively with alteration seen in $67.6 \%, 81.08 \%$ and $48.6 \%$ cases respectively.

Out of 24 cases of liver abscess, $66.7 \%$ cases had altered coagulation profile. The mean PT, APTT and platelet count was $17 \pm 3.6$ seconds, $39.1 \pm 8.7$ seconds and $286.3 \pm 121.8 \times 10^{6} / \mathrm{dl}$ respectively and altered in $58.3 \%, 58.3 \%$ and $4.1 \%$ respectively.

31 cases had hepatic encephalopathy. Out of the 31 cases, $83.9 \%$ had altered coagulation profile. The mean PT, APTT and platelet count were $24.85 \pm 15.36$ seconds, $50.16 \pm 17.29$ seconds and $115.90 \pm 92.41 \times 10^{6} / \mathrm{dl}$ respectively and was altered in $77.4 \%, 77.4 \%$ and $51.6 \%$ cases respectively.

Table 1 Proportion of altered PT, APTT and platelet count

\begin{tabular}{|l|c|c|c|c|c|}
\hline PARAMETER & $\begin{array}{c}\text { RANGE OF } \\
\text { PARAMETER }\end{array}$ & MEAN + SD & $\begin{array}{c}\text { ALTERED } \\
\text { VALUE } \\
(\%)\end{array}$ & $\begin{array}{c}\text { NORMAL } \\
\text { VALUE } \\
(\%)\end{array}$ & $\begin{array}{c}\text { TOTAL } \\
(\%)\end{array}$ \\
\hline $\begin{array}{l}\text { PT } \\
\text { (in seconds) }\end{array}$ & $11.4-86.5$ & $20.6 \pm 9.49$ & $62.9 \%$ & $37.1 \%$ & $100 \%$ \\
\hline $\begin{array}{l}\text { APTT } \\
\text { (in seconds) }\end{array}$ & $25.4-120.9$ & $46.4 \pm 17.35$ & $70 \%$ & $30 \%$ & $100 \%$ \\
\hline $\begin{array}{l}\text { Platelet count } \\
(\mathbf{x ~ 1 0} / \text { dl) }\end{array}$ & $10-575$ & $158.48 \pm 111.23$ & $38.8 \%$ & $61.2 \%$ & $100 \%$ \\
\hline
\end{tabular}


Table 2 PT in patients with liver diseases

\begin{tabular}{|l|c|c|c|c|c|}
\hline DIAGNOSIS & $\begin{array}{c}\text { PT RANGE (IN } \\
\text { SECONDS) }\end{array}$ & $\begin{array}{c}\text { MEAN } \mathbf{\text { SD }} \\
\text { (IN } \\
\text { SECONDS) }\end{array}$ & $\begin{array}{c}\text { ALTERED } \\
\text { PT } \\
\mathbf{n}(\boldsymbol{\%})\end{array}$ & $\begin{array}{c}\text { NORMAL } \\
\text { PT } \\
\mathbf{n}(\boldsymbol{\%})\end{array}$ & $\begin{array}{c}\text { TOTAL } \\
\text { CASES } \\
\text { n(\%) }\end{array}$ \\
\hline Chronic liver disease & $11.4-86.5$ & $22.6 \pm 11.5$ & $60(56 \%)$ & $47(44 \%)$ & $107(100 \%)$ \\
\hline Liver abscess & $12.4-26.5$ & $17 \pm 3.6$ & $14(58.3 \%)$ & $10(41.7 \%)$ & $24(100 \%)$ \\
\hline Liver SOL & $12.4-19.4$ & $15.06 \pm 2.3$ & $3(30 \%)$ & $7(70 \%)$ & $10(100 \%)$ \\
\hline ACLF & $14.6-39.7$ & $23.4 \pm 8.3$ & $8(88.9 \%)$ & $1(11.1 \%)$ & $9(100 \%)$ \\
\hline Acute viral hepatitis & $14-35.5$ & $20 \pm 7.2$ & $4(50 \%)$ & $4(50 \%)$ & $8(100 \%)$ \\
\hline Alcoholic hepatitis & $12.4-30$ & $21 \pm 7.2$ & $5(71.4 \%)$ & $2(28.6 \%)$ & $7(100 \%)$ \\
\hline Fatty liver & $12-13.2$ & $12.8 \pm 0.5$ & $0(0 \%)$ & $5(100 \%)$ & $5(100 \%)$ \\
\hline
\end{tabular}

Table 3 APTT in patients with liver diseases

\begin{tabular}{|l|c|c|c|c|c|}
\hline DIAGNOSIS & $\begin{array}{c}\text { APTT RANGE } \\
\text { (IN SECONDS) }\end{array}$ & $\begin{array}{c}\text { MEAN }+ \text { SD } \\
\text { (IN } \\
\text { SECONDS }\end{array}$ & $\begin{array}{c}\text { ALTERED } \\
\text { APTT } \\
\text { n(\%) }\end{array}$ & $\begin{array}{c}\text { NORMAL } \\
\text { APTT } \\
\text { n(\%) }\end{array}$ & $\begin{array}{c}\text { TOTAL } \\
\text { n(\%) }\end{array}$ \\
\hline Chronic liver disease & $25.4-114.7$ & $49.2 \pm 17.3$ & $68(63.5 \%)$ & $39(36.5 \%)$ & $107(100 \%)$ \\
\hline Liver abscess & $26.1-61$ & $39.1 \pm 8.7$ & $14(41.7 \%)$ & $10(41.7 \%)$ & $24(100 \%)$ \\
\hline Liver SOL & $28.3-44.6$ & $35.2 \pm 5.2$ & $4(40 \%)$ & $6(60 \%)$ & $10(100 \%)$ \\
\hline ACLF & $36.7-81.2$ & $52 \pm 13.1$ & $9(100 \%)$ & $0(0 \%)$ & $9(100 \%)$ \\
\hline Acute viral hepatitis & $30.2-64.2$ & $41.1 \pm 11.7$ & $4(50 \%)$ & $4(50 \%)$ & $8(100 \%)$ \\
\hline Alcoholic hepatitis & $29.8-120.4$ & $52.7 \pm 32.3$ & $3(42.9 \%)$ & $4(57 \%)$ & $7(100 \%)$ \\
\hline Fatty liver & $28.3-32.7$ & $30.8 \pm 1.6$ & $0(0 \%)$ & $5(100 \%)$ & $5(100 \%)$ \\
\hline
\end{tabular}

Table 4 Platelet count in patients with liver disease

\begin{tabular}{|c|c|c|c|c|c|}
\hline DIAGNOSIS & $\begin{array}{c}\text { PLATELET } \\
\text { COUNT } \\
\text { RANGE } \\
\left(\times 10^{6} / \mathrm{dl}\right)\end{array}$ & $\begin{array}{c}\text { MEAN } \pm \text { SD } \\
\left(\times 10^{6} / \mathrm{dl}\right)\end{array}$ & $\begin{array}{c}\text { ALTERED } \\
\text { PLATELET } \\
\text { COUNT } \\
\text { n(\%) }\end{array}$ & $\begin{array}{c}\text { NORMAL } \\
\text { PLATELET } \\
\text { COUNT } \\
\text { n(\%) }\end{array}$ & $\begin{array}{l}\text { TOTAL } \\
\text { n(\%) }\end{array}$ \\
\hline $\begin{array}{ll}\begin{array}{l}\text { Chronic } \\
\text { disease }\end{array} & \text { liver } \\
\end{array}$ & $10-450$ & $118.8 \pm 83.1$ & $45(42 \%)$ & $62(58 \%)$ & $107(100 \%)$ \\
\hline Liver abscess & $86-575$ & $286.3 \pm 121.8$ & $1(4.1 \%)$ & $23(95.9 \%)$ & $24(100 \%)$ \\
\hline Liver SOL & $128-347$ & $218.5 \pm 61.5$ & $0(0 \%)$ & $10(100 \%)$ & $10(100 \%)$ \\
\hline ACLF & $43-406$ & $115.7 \pm 114.5$ & $5(55.6 \%)$ & $4(44.4 \%)$ & $9(100 \%)$ \\
\hline Acute viral hepatitis & $30-277$ & $156.3 \pm 77.9$ & $2(25 \%)$ & $6(75 \%)$ & $8(100 \%)$ \\
\hline Alcoholic hepatitis & $42-280$ & $167.1 \pm 97.9$ & $2(28.6 \%)$ & $5(71.4 \%)$ & $7(100 \%)$ \\
\hline Fatty liver & $106-270$ & $208.8 \pm 66.7$ & $0(0 \%)$ & $5(100 \%)$ & $5(100 \%)$ \\
\hline
\end{tabular}

Table 5 Coagulation profile in cirrhosis

\begin{tabular}{|l|c|c|c|c|c|}
\hline PARAMETER & RANGE & MEAN \pm SD & $\begin{array}{c}\text { ALTERED } \\
\mathbf{n}(\%)\end{array}$ & $\begin{array}{c}\text { NORMAL } \\
\mathbf{n}(\%)\end{array}$ & $\begin{array}{c}\text { TOTAL } \\
\mathbf{n}(\%)\end{array}$ \\
\hline $\begin{array}{l}\text { PT } \\
\text { (in seconds) }\end{array}$ & $11.4-86.5$ & $22.69 \pm 10.57$ & $82(71.3 \%)$ & $33(28.7 \%)$ & $115(100 \%)$ \\
\hline $\begin{array}{l}\text { APTT } \\
\text { (in seconds) }\end{array}$ & $25.4-120.9$ & $49.81 \pm 17.94$ & $94(81.7 \%)$ & $21(18.3 \%)$ & $115(100 \%)$ \\
\hline $\begin{array}{l}\text { Platelet count } \\
\text { (x 10\%/dl) }\end{array}$ & $10-504$ & $125.04 \pm 94.99$ & $60(52.2 \%)$ & $55(47.8 \%)$ & $115(100 \%)$ \\
\hline
\end{tabular}

\section{Discussion}

The age distribution was 17-70 years with a mean of $43.9 \pm 12$ years which was similar to the age distribution of 15 - >60 years as observed by Sohail Ahmed Siddiqui et al ${ }^{[3]}$.

Out of the 115 cases of cirrhosis, $81.7 \%$ were male and $18.3 \%$ were female. This male preponderance was similar to the observation made by Varnika Rai et $\mathrm{al}^{[4]}$ and Jaeyoung Cho et $\mathrm{al}^{[5]}$. Female preponderance was seen in the study conducted by Andreas Drolz et al ${ }^{[6]}$. This may be due to the socioeconomic reasons.

Alcohol was the most common cause of cirrhosis in the present study. This finding is similar to 
Andreas Drolz et $\mathrm{al}^{[6]}$ while hepatitis virus infection was the most common cause of cirrhosis in the study conducted by Jaeyoung Cho et al ${ }^{[5]}$, Varnika Rai et al ${ }^{[4]}$ and Sohail Ahmed Siddiqui et $\mathrm{al}^{[3]}$. This difference may be due to the difference in the socioeconomic practices of the study population.

PT was found to be altered in $71.3 \%$ cases of cirrhosis while it was normal in $28.7 \%$ cases which is similar to that observed by Jaeyoung Cho et $\mathrm{al}^{[5]}$, Sohail Ahmed Siddiqui et $\mathrm{al}^{[3]}$ and KyungHwa Shin et al ${ }^{[7]}$. APTT was found to be altered in $81.7 \%$ cases while it was normal in $18.3 \%$ cases. These findings were similar to that observed by Sohail Ahmed Siddiqui et al ${ }^{[3]}$. Platelet count was found to be altered in $52.2 \%$ cases while it was normal in $47.8 \%$ cases. These findings were similar to that observed by Varnika Rai et al ${ }^{[4]}$, Kyung-Hwa Shin et $\mathrm{al}^{[7]}$ and Andreas Drolz et $\mathrm{al}^{[6]}$.

In the present study PT and APTT alterations were found to be similar in alcoholic cirrhosis as compared to the other types of liver diseases while platelet count was found to be significantly increased in alcoholic cirrhosis ( $p$ value $<0.001$ ) as compared to other types of liver diseases.

Out of the 24 cases of liver abscess studied, PT was found to be altered in $58.3 \%$ cases. This finding is similar to the observation made by Dhaval O. Mangukiya et $\mathrm{al}^{[8]}$.

Out of the 10 cases of liver SOL studied, PT and APTT were altered in $30 \%$ and $40 \%$ cases respectively. This is in accordance with the findings of Xue-Ping Wang et al ${ }^{[9]}$. Platelet count was normal in all cases of liver SOL in present study as opposed to $46.01 \%$ observed in Xue-Ping Wang et al ${ }^{[9]}$. This difference may be due to the difference in total study population.

\section{Conclusion}

Coagulation profile was found to be significantly altered in cases of chronic liver disease. Chronic liver disease was more common in males as compared to females. This alteration in coagulation profile can lead to mild to severe life threatening bleeding or thrombotic complications in patients with liver disease. Considering this, regular monitoring of coagulation profile should be done for appropriate and timely detection and management of such patients.

\section{Compliance with Ethical Standards}

Funding: No funding was received for the present study.

Ethical approval: All procedures performed in studies involving human participants were in accordance with the ethical standards of the institutional and/or national research committee and with the 1964 Helsinki declaration and its later amendments or comparable ethical standards. Informed consent: Informed consent was obtained from all individual participants included in the study.

\section{Reference}

1. Fauci AS, Braunwald E, Kasper DL, Hauser SL, Longo DL, Jameson JL et al. Harrison's Principle of internal medicine19 $9^{\text {th }}$ edition. McGraw Hill. 2012;2:2520-31.

2. Stephen H. Caldwell, Maureane Hoffman, Ton Lisman, B. Gail Macik, Patrick G Northup, K. Rajender Reddy et al. Coagulation disorders and hemostasis in liver disease: pathophysiology and critical assessment of current management. Hepatology. Oct 2006;44(4):1039-46.

3. Sohail Ahmed Siddiqui, Ahmed M, Muhammad Hanif Ghani, Muhammad Anwar Menon, Ghulam Mustafa, Muhammad Aslam Ghori. Coagulation abnormalities in patients with chronic liver disease in Pakistan. Journal of Pakistan Medical Association. April 2011;61(4):363-7.

4. Varnika Rai, Neeraj Dhameja, Sandip kumar, Jyoti Shukla, Rajeev Singh, Vinod Kumar Dixit. Haemostatic Profile of Patients with Chronic Liver Disease- its Correlation with Severity and Outcome. Journal of Clinical and Diagnostic Research. Aug 2017;11(8):24-6. 
5. Jaeyoung Cho, Sun Mi Choi1, Su Jong Yu, Young Sik Park, Chang-hoon Lee, Sangmin Lee. Bleeding complications in critically ill patients with liver cirrhosis. korean Journal of Internal Medicine. 2016;31:288-95.

6. Andreas Drolz, Thomas Horvatits, Kevin Roedl, Karoline Rutter, Katharina Staufer, Nikolaus Kneidinger. Coagulation parameters and major bleeding in critically ill patients with cirrhosis. Hepatology. 2016;64:556-68.

7. Kyung-Hwa Shin, M.D., In-Suk Kim, M.D., Hyun Ji Lee, M.D., Hyung-Hoi Kim, M.D., Chulhun L. Chang, M.D., Young Mi Hong, M.D. Thromboelastographic Evaluation of Coagulation in Patients With Liver Disease. Annals of Laboratory Medicine. 2017;37:204-12.

8. Dhaval O. Mangukiya, Jitendra R. Darshan, Vijay K. Kanani, Saurabh T. Gupta. A Prospective Series Case Study of Pyogenic Liver Abscess: Recent Trands in Etiology and Management. Indian Journal of Surgery. September-October 2012;74(5):385-90.

9. Xue-Ping Wang, Min- Jie Mao, ZhongLian He, Lin Zhang, Pei-Dong Chi, Jia-rui $\mathrm{Su}$. A retrospective discussion of the prognostic value of combining prothrombin time(PT) and fibrinogen(Fbg) in patients with Hepatocellular Carcinoma. Journal of Cancer. 2017;8(11):2079-87. 